\title{
Novel fenofibrate adverse effect in resistant hypertension: A case report
}

\author{
Deena M. S. Barrouq ${ }^{1}$, Tareq Irshaidat ${ }^{2,{ }^{*}}$
}

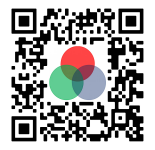

Use your smartphone to scan this QR code and download this article

${ }^{1}$ Department of Family Medicine,

Ministry of Health, Jordan

${ }^{2}$ Department of Chemistry, College of Sciences, Al-Hussein Bin Talal

University, Maian, Jordan

\section{Correspondence}

Tareq Irshaidat, Department of Chemistry, College of Sciences, Al-Hussein Bin Talal University, Ma'an, Jordan

Email: tirshaidat@yahoo.com

History

- Received: Sep 14, 2020

- Accepted: Oct 16, 2020

- Published: Oct 31, 2020

DOI : 10.15419/bmrat.v7i10.640

\section{Check for updates}

\section{Copyright}

( $)$ Biomedpress. This is an openaccess article distributed under the terms of the Creative Commons Attribution 4.0 International license.

\begin{abstract}
Background: Silent uncontrolled hypertension can cause major organ damage. Case presentation: A 42-year-old hypertensive male used fenofibrate to lower his triglyceride levels; however, the investigation revealed that it caused a significant increase in the desire and ingestion of greasy food items which caused fluctuating high blood pressure. Correction of the dietary regimen and a modification in the usual recommended drug dose led to a significant positive development of the medical case. Specifically, it was successful in adjusting the systolic and diastolic blood pressure components and blood test parameters, and was effective in correcting the glucose criteria back to the acceptable standard range. Conclusion: This is the first evidence in the literature on a poorly controlled hypertension case associated indirectly with fenofibrate.

Key words: Fenofibrate, triglycerides, total cholesterol, dietary intervention, hypertension, dyslipidemia
\end{abstract}

\section{INTRODUCTION}

The increase in blood pressure, a silent killer, is one of the most common long-lasting illnesses among patients in major health care programs ${ }^{1}$. Age, obesity, and dyslipidemia are the main risk factors for primary (essential) hypertension, and which contribute to most of the cases. On the other hand, secondary hypertension might be due to some drugs, kidney disorders, endocrine diseases, and cancer. To make a diagnosis of hypertension, it is typically desirable to record high blood pressure values (with systolic and diastolic blood pressure components equal or above 140 or $90 \mathrm{mmHg}$, respectively) in quite a few sequential detached occurrences. The probable whys and wherefores may be recognized by reviewing the individual medical history and numerous biochemical considerations. At an early phase, the primary hypertension may be treated entirely by amending the standards of living; on the other hand, failure to succeed demands the addition of one or more prescription drugs.

Ordinarily, among the patients who attend our health care centers and emergency rooms, the high blood pressure is well-ordered and pulled down using one or a combination of hypertension medications. It has been noted that more perplexing cases frequently arise when the patient has upper-range concentrations of plasma lipids than the standard acceptable values. In such cases, triglyceride- and cholesterollowering medications are prescribed which, in the long run, support the control of hypertension efficaciously.

\section{CASE PRESENTATION}

A 42-year-old man was presented to our comprehensive health care clinic in the morning; he complained of a tireless and annoying strong general headache. He was $186 \mathrm{~cm}$ in height and $115 \mathrm{~kg}$ in weight, with a body mass index (BMI) of $33.3 \mathrm{~kg} / \mathrm{m}^{2}$, which classified him as an obese individual. He did not have a history of alcohol ingestion nor of smoking, but used to drink coffee daily (a maximum of two 250-ml cups/day). He indicated that the postulated cause of his headache was an absence of sufficient sleep since he used paracetamol $(500 \mathrm{mg})$ to treat the headache episodes, one or two times per day over the last ten days. He admitted himself to the treatment center as the headache persisted. His blood pressure measurement reading was 170/110 (systolic/diastolic) while resting, which indicated that he had high blood pressure on that visit. The patient was given amlodipine ( $5 \mathrm{mg}$ as crushed tablet) but after two hours, the high blood pressure persisted (165/104 $\mathrm{mmHg}$ ), after which furosemide $(40 \mathrm{mg}$ ) was given intravenously with continuing servings of low-ion water. After four hours, his blood pressure evaluation declined to 148/93 and he expressed that the headache strength dropped noticeably too. The patient was asked to continue his systematic medications and to measure the blood pressure on the following two days before noon 
Table 1: The laboratory blood analysis results; the initial and after three months

\begin{tabular}{lccc}
\hline Test & Normal range & Initial & After 3-months \\
Glucose $(\mathrm{mg} / \mathrm{dL})$ & $70-100$ & 111 & 89 \\
HbAlc $(\%)$ & $4.0-5.6$ & 6.6 & 5.3 \\
Triglycerides $(\mathrm{mg} / \mathrm{dL})$ & $<150$ & 351 & 155 \\
Total Cholesterol $(\mathrm{mg} / \mathrm{dL})$ & $<200$ & 302 & 194 \\
Creatinine $(\mu \mathrm{mol} / \mathrm{L})$ & $53-97$ & 58 & 73 \\
Sodium $(\mathrm{mmol} / \mathrm{L})$ & $136-145$ & 145 & 140 \\
Potassium $(\mathrm{mmol} / \mathrm{L})$ & $3.5-5.1$ & 3.5 & 4.8 \\
Magnesium $(\mathrm{mmol} / \mathrm{L})$ & $0.66-1.07$ & 0.66 & 0.84 \\
Calcium $(\mathrm{mmol} / \mathrm{L})$ & $2.2-2.5$ & 2.3 & 2.4 \\
Chloride $(\mathrm{mmol} / \mathrm{L})$ & $95-110$ & 109 & 100 \\
\hline
\end{tabular}

in advance of eating or drinking coffee; the readings were $162 / 109$ and 159/108.

The patient's medical history was acquired on his first appearance in the clinic. One year prior, the patient was diagnosed with hypertension with similar strong headache episodes. The analysis at that time discovered that he had high plasma lipids, triglycerides, and total cholesterol (details of the report were not accessible). He was given oral medications: amlodipine ( $5 \mathrm{mg} /$ day in the morning), fenofibrate (200 mg/day in the morning), and simvastatin (20 $\mathrm{mg} /$ day at night). As he indicated, with time the blood pressure and lipids improved slightly and the strong headache episodes were not as common anymore. He continued these medications but after six months from the first episode he experienced, there was an onset of similar symptoms including infuriating headache, high blood pressure, and high plasma lipids, regardless of his commitment to taking the exact daily drug dose which was prescribed. His medical doctor instructed him to continue to take the identical doses of simvastatin and fenofibrate but to change the hypertension prescription to a mixture of three medications (commercially accessible as one pill) which included amlodipine (5 mg), hydrochlorothiazide (12.5 $\mathrm{mg}$ ), and olmesartan medoxomil (40 mg). He pointed out that this prescription alteration improved both the systolic and diastolic readings over a period of six months. Recently, the patient started again to suffer from the headache episodes after which he was presented to the clinic (his first visit). His case was interesting and needed in-depth investigation. The details of his treatment plan are presented in the discussion section.

\section{MANAGEMENT AND DISCUSSION}

The fundamental blood examination of the patient was conducted following an overnight 12-hour fasting; the outcomes are presented in Table 1. The blood glucose and glycosylated (glycated) hemoglobin data were found to be slightly above the normal range which indicated that the patient was pre-diabetic. First and foremost, he was instructed to decrease the ingestion of carbohydrate-rich food items, all kinds of desserts, as well as decrease the consumption of table sugar by replacement with natural low-calorie sweetener, if accessible. Also, the results indicated elevated plasma lipid, sodium, and chloride concentrations, but low potassium and magnesium concentrations. The values in Table 1 are consistent with high blood pressure readings and puts forward two possibilities. First, the patient did not take his drugs regularly and/or he had a troubled dietary regimen. The patient claimed that he took his medications every day at the identical time schedule and did not miss any prescribed amount. Based on this information, the second possibility must be his nutritional regimen.

The patient mentioned a very important point. $\mathrm{He}$ noticed that his appetite toward fatty food items that he liked amplified noticeably after he started taking the triglyceride and cholesterol medications. Exploring his current ingestion of food per week showed that he had unbalanced dietary components. He consumed nearly $1000 \mathrm{~g} /$ week of red meat (on three separate days; each was on average $330 \mathrm{~g}$ ), $500 \mathrm{~g} /$ week of chicken meat (on two separate days; each was nearly $250 \mathrm{~g}$ ), and two fried eggs/day. The patient illustrated that one of his beloved food items was natural cow-milk butter. He used it very often as a dip for date fruit, with rice, with cooked vegetables, in 
baked desserts, and with honey as a spread. He believed that butter was very nutritive and supported him with the energy that he needed for the day. From all of the aforementioned details, his meals were noticeable sources of triglycerides and cholesterol (and other steroids). Despite using the medications, the high lipid food sources were main contributing factors to his health problem ${ }^{2}$, decreasing vascular flexibility and stimulating water retention. As a result, the development of chronic hypertension occurred. In addition to these factors and as part of his diet, the consumption of coffee ( $250 \mathrm{ml}$ twice/day) also contributed to some extent in the poorly managed hypertension.

Based on the patient's disclosures, the hypothesis was that appetite stimulation toward fat-rich food items occurred due to the lipid medications. Therefore, the patient was asked to decrease the fenofibrate dosage to $100 \mathrm{mg} /$ day (half a tablet) in the morning, while keeping the simvastatin dose unchanged in the evening (20 mg/day). The other important revelation is that the nature of his diet, consisting of many lipid-rich food components, was critical for inducing the development of repeated hypertension episodes ${ }^{2-4}$. Therefore, he was given the following instructions to be followed for three months. He was asked to avoid the table salt as much as possible ${ }^{5}$, to decrease the total consumption of red meat to $400 \mathrm{mg} /$ week (on two to three separate occasions per week; no apparent white fat), to decrease chicken consumption to two boneless skinless chicken breasts (boiled or grilled with or without salt-free flavoring herbs), to consume more vegetables of all kinds ${ }^{6}$ (preferentially fresh vegetables without cooking if possible), to completely stop the consumption of natural cow-milk butter, to decrease the consumption of all oils (specially fried food items), and to stop the consumption of any hydrogenated oils (popular in commercial desert products), to adhere to a minimal consumption of sweets of all kinds (including natural sweets like honey), to watch the coffee consumption and to try to limit it to 200 $\mathrm{ml} /$ day (100 $\mathrm{ml}$ twice/day, if possible), and to decrease his total egg consumption to two eggs per week. Also, the patient was instructed to take one multi-vitamin supplement every day with the main meal.

His blood pressure was examined in the treatment center every week over a period of twelve weeks. The fasting blood glucose, the glycosylated hemoglobin (HbA1c; \%), and lipids (plasma triglycerides and total cholesterol) were measured every month over a period of three months. It seemed that the patient adhered strictly to the instructions as noticed from his weight; he lost about $7 \mathrm{~kg}$ during the three-month period which was an outstanding achievement compared to other cases that we follow. The blood pressure readings improved gradually and a decrease in both the systolic and diastolic pressure values was observed. After the twelve-week monitoring period, the reading was 132/81 (with the medications). Pleasantly, after three months the glucose parameters (fasting blood glucose and the $\mathrm{HbAlc}$ readings) returned to the ideal normal ranges $(89 \mathrm{mg} / \mathrm{dL}$ and $5.3 \%$, respectively). Moreover, the triglycerides, the total cholesterol, sodium, potassium, magnesium, and chloride concentrations improved significantly and returned to the normal ranges ${ }^{7,8}$. The patient indicated that his strong desire toward fatty food items decreased significantly and there was not any noticeable challenge in following the new regimen.

\section{CONCLUSION}

It has been noted that in a few of our patient cases (> 40 years old) of poorly managed hypertension that the fenofibrate medication has been associated with a stimulation of appetite toward fat-rich food items ("toward-fat" rush). Unfortunately, verbal advice alone was not effective. The difficulty is that in this situation, it is not straight forward to measure or diagnose the appetite induction. As a call to all physicians around the world, a successful life-saving treatment of such cases (poorly-managed hypertension with dyslipidemia) can be achieved by a triglyceride medication dose reduction and a diet correction (personalized planning of the medication dose and of the diet, if possible). This is the first characterized case of its type in the literature.

\section{ABBREVIATIONS}

None.

\section{ACKNOWLEDGMENTS}

None.

\section{AUTHOR'S CONTRIBUTIONS}

DB contributed in acquisition of data, analysis and interpretation of data, revising the manuscript, and has given final approval of the version to be published. TI contributed in analysis and interpretation of data, writing the manuscript, and has given final approval of the version to be published. All authors read and approved the final manuscript.

\section{FUNDING}

This research received no specific grant from any funding agency in the public, commercial, or not-forprofit sectors. 


\section{AVAILABILITY OF DATA AND MATERIALS}

Not applicable.

\section{ETHICS APPROVAL AND CONSENT TO PARTICIPATE}

This study was conducted in accordance with the amended Declaration of Helsinki.

Written informed consent was obtained from the patient for publication of this Case Report. A copy of the written consent is available for review by the Editorin-Chief of this journal.

\section{CONSENT FOR PUBLICATION}

Not applicable.

\section{COMPETING INTERESTS}

The authors declare that they have no competing interests.

\section{REFERENCES}

1. Kearney PM, Whelton M, Reynolds K, Whelton PK, He J. Worldwide Prevalence of Hypertension: a Systematic Review. J Hypertens. 2004;22(1):11-19. PMID: 15106785. Available from: https://doi.org/10.1097/00004872-200401000-00003.
2. Lithell H. Hypertension and Hyperlipidemia: A Review. Am J Hypertens. 1993;6(11):303S-308S. PMID: 8297536. Available from: https://doi.org/10.1093/ajh/6.11.303S.

3. SchwingshackI L, Hoffmann G. Diet Quality as Assessed by the Healthy Eating Index, the Alternate Healthy Eating Index, the Dietary Approaches to Stop Hypertension Score, and Health Outcomes: A Systematic Review and Meta-Analysis of Cohort Studies. J Acad Nutr Diet. 2015;115(5):780-800. PMID: 25680825. Available from: https://doi.org/10.1016/j.jand.2014. 12.009.

4. Schwingshackl L, Chaimani A, Schwedhelm C, Toledo E, Pünsch M, Hoffmann G, Boeing H. Comparative effects of different dietary approaches on blood pressure in hypertensive and prehypertensive patients: A systematic review and network metaanalysis. Crit Rev Food Sci Nutr. 2019;59(16):2674-2687. PMID: 29718689. Available from: https://doi.org/10.1080/10408398. 2018.1463967.

5. He FJ, MacGregor GA. Plasma sodium and hypertension. Kidney Int. 2004;66(6):2454-2466. PMID: 15569339. Available from: https://doi.org/10.1111/j.1523-1755.2004.66018.x.

6. Munoz JM, Sandstead HH, Jacob RA, Logan GM, Reck SJ, Klevay $L M$, Dintzis FR, Inglett GE, Shuey WC. Effect of some Cereal Brans and Textured Vegetable Protein on Plasma Lipids. Am J Clin Nut. 1979;32(3):580-592. PMID: 420150. Available from: https://doi.org/10.1093/ajen/32.3.580.

7. Khan HA, Sobki SH, Khan SA. Association between glycaemic control and serum lipids profile in type 2 diabetic patients: HbA1c predicts dyslipidaemia. Clin Exp Med. 2007;7(1):2429. PMID: 17380302. Available from: https://doi.org/10.1007/ s10238-007-0121-3.

8. Houston MC, Harper KJ. Potassium, Magnesium, and Calcium: Their Role in Both the Cause and Treatment of Hypertension. J Clin Hypertens. 2008;10(7):3-11. PMID: 18607145. Available from: https://doi.org/10.1111/j.1751-7176.2008.08575.x. 